\title{
Endovascular treatment of middle cerebral artery aneurysms - single-centre results
}

\author{
Paweł Brzegowy ${ }^{1 A, D, E}$, Jakub Polak ${ }^{2 B, C, D, E, F}$, Jakub Wnuk ${ }^{2 B, C, D, E, F}$, Bartłomiej Łasocha ${ }^{3 B}$, Borys Kwinta ${ }^{4 D}$, \\ Andrzej Urbanik ${ }^{1 \mathrm{E}}$, Tadeusz J. Popiela ${ }^{1 \mathrm{~B}, \mathrm{E}}$ \\ 'Chair of Radiology, Faculty of Medicine, Jagiellonian University Medical College, Krakow, Poland \\ 2Students'Scientific Group, Chair of Radiology, Faculty of Medicine, Jagiellonian University Medical College, Krakow, Poland \\ ${ }^{3}$ Department of Radiology, University Hospital in Krakow, Poland \\ ${ }^{4}$ Department of Neurosurgery and Neurotraumatology, Faculty of Medicine, Jagiellonian University Medical College, Krakow, Poland
}

\section{Abstract}

Purpose: The middle cerebral artery (MCA) is the second most common location of intracerebral aneurysms. Traditionally, they are treated by microsurgical clipping, but with the development of new techniques and devices endovascular embolisation is gaining more importance. The aim of this study was to summarise six years of experience of our department in endovascular treatment of MCA aneurysms.

Material and methods: Forty patients with 41 MCA aneurysms treated in a single centre were included in this study. Data on patients' comorbidities, aneurysm morphology, and treatment course were collected, with special emphasis on complications.

Results: There were no statistically significant differences in terms of aneurysm morphology between males and females and between ruptured and unruptured aneurysms. None of the diseases analysed in the current study were linked with significantly increased risk of SAH. Unruptured aneurysms were significantly more frequently treated by stent-assisted coiling ( $30.4 \%$ vs. $5.6 \%, p=0.0388)$ than were ruptured aneurysms, while ruptured aneurysms were treated more frequently by coiling alone $(77.8 \%$ vs. $34.8 \%, p=0.0062)$. After an initial course of treatment $63.4 \%$ $(n=26)$ of patients had class I in Raymond-Roy occlusion classification, 22\% $(n=9)$ had class II, and 14.6\% $(n=6)$ had class III. Complications of the procedure were observed in $17.5 \%(n=7)$ of patients: $22.2 \%(n=4)$ with ruptured and $13.6 \%(n=3)$ with unruptured aneurysms.

Conclusions: Endovascular treatment of MCA aneurysms is feasible, and our results are convergent with other studies. Ruptured MCA aneurysms may be treated endovascularly with similar effects as unruptured MCA aneurysms. The complication rate of such treatment is low.

Key words: endovascular treatment, MCA aneurysm, stent-assisted coiling.

\section{Introduction}

The middle cerebral artery (MCA) is one of the most frequent locations of intracranial aneurysms (IA). Their share of IA ranges from 20 to $43 \%[1,2]$. The basic approach to MCA aneurysm treatment is neurosurgical clipping, which is well established [3-6]. Moreover, ruptured MCA aneu- rysms usually require surgical treatment of the adjacent haematoma [7]. At the same time, endovascular therapy for MCA aneurysms is available, with the first study comparing MCA aneurysm clipping and endovascular treatment published in 1999 [4]. The endovascular treatment of intracranial aneurysms is developing rapidly. The role of the endovascular approach in MCA aneurysm treatment is

Correspondence address:

Dr. Paweł Brzegowy, Chair of Radiology, Jagiellonian University Medical College, 19 Kopernika St., 31-501 Krakow, Poland, phone: +48 124001509 ,

e-mail: pawelbrzegowy007@gmail.com

Authors' contribution:

A Study design - B Data collection - C Statistical analysis - D Data interpretation - E Manuscript preparation - F Literature search · G Funds collection 
constantly increasing, with new devices allowing for treatment of more complex aneurysms [7-10].

MCA aneurysms are considered challenging for endovascular treatment due to the anatomy of MCA and their localisation. The diameter of MCA is relatively small, and aneurysms often incorporate branches arising from MCA trunk. The choice of treatment method should be based on size, location, and neck size of the aneurysm, as well as comorbidities and patients' age. The choice between clipping and endovascular procedure, as well as between different types of endovascular procedures, is crucial for the success of treatment.

Intracranial aneurysms are the most common cause of subarachnoid haemorrhage (SAH). It often occurs in young patients and is the cause of loss of productive life years in the same rate as seen in cerebral stroke [11]. It is estimated that about $50 \%$ of patients with an SAH episode die and $20 \%$ suffer from its complications [12].

Advances in technology have led to an increase in the number of aneurysms treated by endovascular procedures. Nonetheless, more data are needed to support their quality and safety. The aim of this study was to summarise the eight years of experience of our department in endovascular treatment of MCA aneurysms, and to compare the results of treatment of ruptured and unruptured aneurysms.

\section{Material and methods}

After obtaining approval from the institutional Bioethics Committee, we retrospectively assessed all procedures of endovascular treatment of intracranial aneurysms from 2013 to 2018. All patients aged 18 years and older, who had undergone embolisation of MCA aneurysm, were included.

Forty patients with $41 \mathrm{MCA}$ aneurysms were treated. Eighteen (45\%) men with 19 (46.3\%) aneurysms were included in this group. Mean age of patients was 56.15 $( \pm 13.86$; range $25-92)$ years. In our group, $43.9 \%(n=18)$ of patients had SAH due to MCA aneurysm rupture, while $56.1 \%(n=23)$ were treated for unruptured aneurysms.

The procedures were performed under general anaesthesia with the use of a mono-plane Axiom Artis dFA angiography system equipped with 3D DSA and Dyna CT connected with workstation reconstruction software (Siemens Healthcare, Erlangen, Germany).

In all patients who underwent the procedure, data on age and sex, neurological status (assessed with the Glasgow Coma Scale, Hunt-Hess scale, and World Federation of Neurosurgical Societies scale), and incidence of subarachnoid haemorrhage were collected. The incidence of comorbidities, such as: hypertension, diabetes, ischaemic heart disease, hypercholesterolaemia, obesity, lung, kidney, and liver diseases, and history of myocardial infarction, ischaemic stroke, and subarachnoid haemorrhage was also evaluated.
Next, aneurysm morphology was assessed based on three-dimensional digital subtraction angiography (3D DSA) studies. Two independent researchers measured the dimensions. Aneurysm shape, maximal height, maximal width, neck width, and inflow angle were determined. Aneurysm shape was defined as spherical if its height, width, and diameter perpendicular to its width were equal; ellipsoid if only the width and height were equal, and irregular if it could not be categorised into the previous groups. Then, morphological indexes, such as aspect ratio (AR), width-to-height ratio $(\mathrm{WH})$, and bottleneck factor (BNF) and, using AngioCalc calculator (www.angiocalc.com), aneurysm volume and percentage packing volume were calculated. Inflow angle, defined as the angle between parent vessel and maximal height of the aneurysm dome was measured. To evaluate the aneurysm location, they were classified to four groups: in MCA bifurcation, in further branches, by lenticulostriate arteries and by early cortical branches. The M1 segment length was also measured.

The treatment course was evaluated: number of endovascular procedures, recanalisation rate, type of endovascular procedure (coiling, balloon-assisted coiling, stentassisted coiling, Y-stenting, flow diverter, pCONus), as well as the results of embolisation in the Raymond-Roy scale. The recorded complications included bleeding during procedure, relocation of coils during the procedure, formation of thrombus during the procedure, transfer to an intensive care unit, and death.

Continuous variables were analysed using Student's $t$-test or Mann-Whitney test, and categorical variables were analysed using chi-square analysis. In all analyses, $p<0.05$ was considered statistically significant. All statistical analyses were performed using Statistica version 12.5 (StatSoft Inc., Tulsa, OK, USA).

\section{Results}

\section{Morphology of aneurysms and middle cerebral artery}

The localisation of the aneurysms is shown in Figure 1. Aneurysms in bifurcation of MCA were the most commonly treated. The morphological features of aneurysms

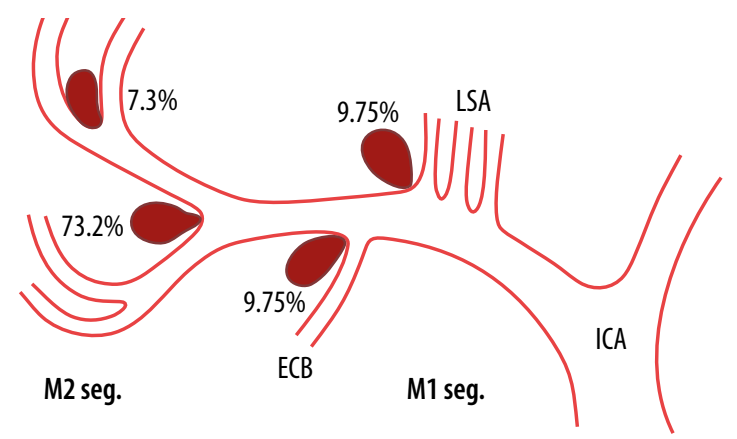

Figure 1. Localization of treated middle cerebral artery aneurysms. ICA - internal carotid artery, LSA - lenticulostriatae arteries, ECB - early cortical branches 
are presented in Table 1 . There were no statistically significant differences in terms of aneurysm morphology between males and females and between ruptured and unruptured aneurysms, although ruptured aneurysms tended to be larger. However, differences in M1 segment length were observed between patients with ruptured and unruptured aneurysms ( $13.3 \pm 3.7$ vs. $17.5 \pm 6.3, p=0.0155)$. M1 segment lengths ranged from $5.3 \mathrm{~mm}$ to $19.8 \mathrm{~mm}$ in patients with ruptured aneurysms and from $7.1 \mathrm{~mm}$ to $33.0 \mathrm{~mm}$ in patients with unruptured aneurysms. $42.5 \%(n=17)$ of patients had multiple aneurysms. $32.4 \%(n=10)$ had one additional aneurysm, $10 \%(n=4)$ had two additional aneurysms, $2.5 \%(n=1)$ had three additional aneurysms, and $5 \%(n=2)$ had four additional aneurysms. $32.5 \%(n=13)$ of patients had additional ipsilateral MCA aneurysms and $7.5 \%(n=3)$ had mirror MCA bifurcation aneurysms.

\section{Comorbidities}

None of the diseases analysed in the current study were linked with significantly increased risk of SAH. Past history of SAH, ischaemic stroke, or myocardial infarction and family history of aneurysms were distributed equally in both groups. Tobacco smoking and alcohol use disorder did not correlate with the incidence of SAH.

\section{Treatment method}

In ruptured aneurysms, 15 patients were treated by coiling alone, two by balloon-assisted coiling, and one by stentassisted coiling. In unruptured aneurysms, seven were treated by coiling alone, three by balloon-assisted coiling, 10 by stent assisted coiling ( 1 Y-stenting), two by flow diverter, and one by pCONus with coils. Three aneurysms treated with stents due to wide neck and high tortuosity of M2 MCA branches were treated with two-stage procedure. In total, 44 endovascular procedures were performed: 38 aneurysms were treated in a one-stage procedure, while three required a planned two-stage procedure.

Five of the unruptured aneurysms were retreated due to recanalisation after surgical clipping (Figure 2A-D). Unruptured aneurysms were significantly more frequently treated by stent-assisted coiling ( $30.4 \%$ vs. $5.6 \%$, $p=0.0388)$ than ruptured aneurysms, while ruptured aneurysms were treated more frequently by coiling alone (77.8\% vs. $34.8 \%, p=0.0062)$. No connection of morphological features and treatment method was found.

\section{Immediate treatment results}

After the initial course of treatment $63.4 \%(n=26)$ of patients had class I aneurysms in Raymond-Roy occlusion classification, $22 \%(n=9)$ had class II, and 14.6\% $(n=6)$ had class III. Mean packing density was $26.20 \pm 0.20 \%$. No significant difference in packing density (30.6\% vs. $20.8 \%$; $p=0.2939$ ) and class in Raymond-Roy occlusion classifi-
Table 1. Morphology of ruptured and unruptured aneurysms. All $p>0.05$

\begin{tabular}{|c|c|c|c|}
\hline Factor & All aneurysms & $\begin{array}{l}\text { Ruptured } \\
\text { aneurysms }\end{array}$ & $\begin{array}{l}\text { Unruptured } \\
\text { aneurysms }\end{array}$ \\
\hline \multicolumn{4}{|c|}{ Aneurysm shape (\%) } \\
\hline Spherical & 51.2 & 44.4 & 56.5 \\
\hline Ellipsoid & 24.4 & 27.8 & 21.7 \\
\hline Irregular & 24.4 & 27.8 & 21.7 \\
\hline \multicolumn{4}{|l|}{ Diameters (mm) } \\
\hline Neck width & 3.44 & 3.48 & 3.42 \\
\hline Maximal height & 4.03 & 4.50 & 3.90 \\
\hline Maximal width & 4.71 & 4.81 & 4.60 \\
\hline Width 2 & 3.95 & 4.66 & 3.80 \\
\hline$A R$ & 1.15 & 1.24 & 1.13 \\
\hline WH & 1.14 & 1.23 & 1.31 \\
\hline BNF & $1.44( \pm 0.52)$ & $1.57( \pm 0.67)$ & $1.33( \pm 0.35)$ \\
\hline \multicolumn{4}{|l|}{ Other } \\
\hline Inflow angle $\left({ }^{\circ}\right)$ & $121.73( \pm 32.29)$ & $125.52( \pm 31.85)$ & $118.76( \pm 33.04)$ \\
\hline Volume $\left(\mathrm{mm}^{3}\right)$ & 31.77 & 69.42 & 20.25 \\
\hline
\end{tabular}

cation ( $1.7 \pm 0.8$ vs. $1.4 \pm 0.6 ; p=0.2085)$ was detected between ruptured and unruptured aneurysms. No connection between treatment method and better outcomes was found.

\section{Complications}

Complications of the procedure were observed in $17.5 \%$ ( $n=7$ out of 40$)$ of patients: $22.2 \%(n=4$ out of 18$)$ with ruptured and $13.6 \%$ ( $n=3$ out of 22$)$ with unruptured aneurysms $(p=0.48)$.

Bleeding from the aneurysm during procedure occurred in $5 \%(n=2)$ of patients. In one patient with SAH the bleeding, which appeared after aneurysm perforation during coil packing, was stopped by balloon inflation. In one patient unruptured aneurysm bleeding, which was a result of microwire perforation of aneurysm sac, was stopped by coil implantation. Relocation of coils into the lumen of the vessel occurred in $5 \%(n=2)$ of patients without flow disturbances and thromboembolic events.

Thromboembolic complications occurred in 5\% $(n=2)$ of patients, both treated with balloon-assisted coiling. In one patient with ruptured aneurysm, mechanical thrombectomy of M1 occlusion was performed, but complete recanalisation was not achieved, and the patient died due to ischaemic changes. In the patient with unruptured aneurysm, asymptomatic ischaemic stroke in an area supplied by the branch originating from the aneurysm neck was detected in postprocedural CT three days after the procedure, with no neurological deficits.

In $2.5 \%(n=1)$ of patients, dissection of the internal carotid artery with no haemodynamic disturbances occurred, but it was complicated by persistent mild aphasia. 

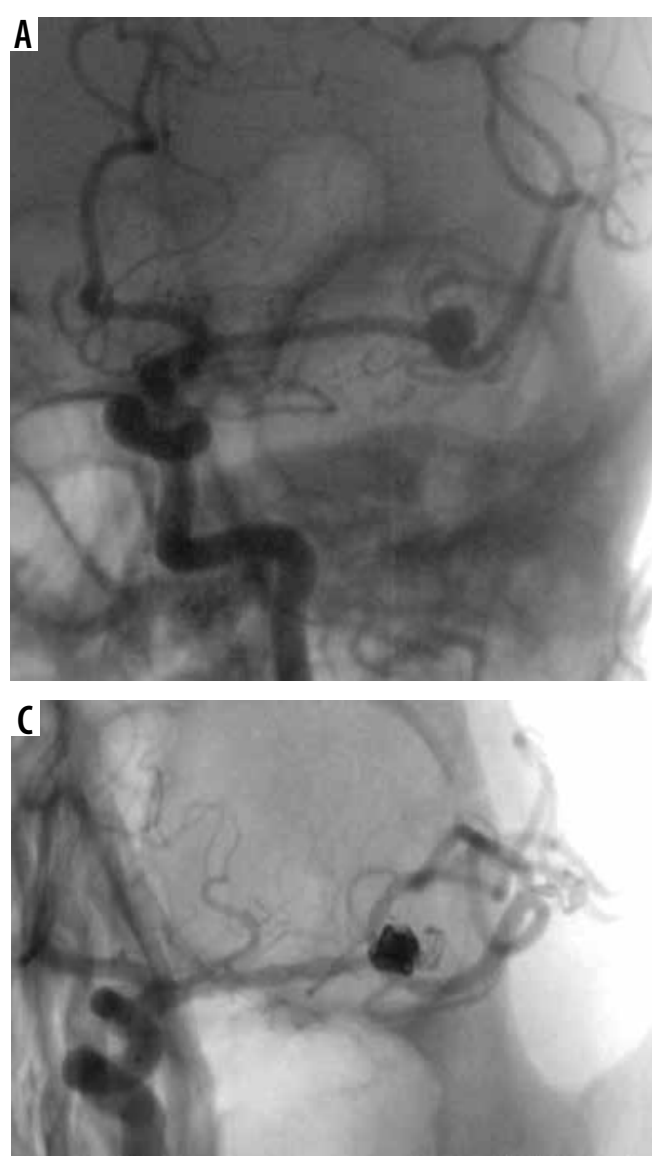

Figure 2. A) Recurrent left middle cerebral artery bifurcation aneurysm after surgical clipping. B-C) Y-stenting coil embolization. Follow-up contrast magnetic resonance angiography (MRA) shows total occlusion of the aneurysm and patency od LMCA branches (D)

Seven patients with SAH required hospitalisation in intensive care unit, and three of them died. Among patients with unruptured aneurysms none died. Aneurysm morphology, aneurysm rupture, method of endovascular treatment, packing density, and neurological state have been found not to be connected with increased risk of intra-procedural complications.

\section{Follow-up}

In $54 \%$ of patients $(n=20)$ diagnostic imaging follow-up (DSA, MRI and CT angiography studies) was available. The mean time of follow-up on diagnostic imaging was 1.6 \pm 1.7 years. Recanalisation occurred in four patients (three with SAH and one without SAH). One unruptured and two ruptured aneurysms were retreated once due to recanalisation and one ruptured aneurysm had two treatments of recanalisation. Recanalisation of aneurysms was treated by coiling alone in one case, by stenting alone in one case, by stent-assisted coiling in two cases, and by pCONus with coils in one case. All treatments of recanalisation achieved class I in Raymond-Roy occlusion classification.

Clinical follow-up 30 days after the procedure was available for eight patients, with six patients scoring 0 points
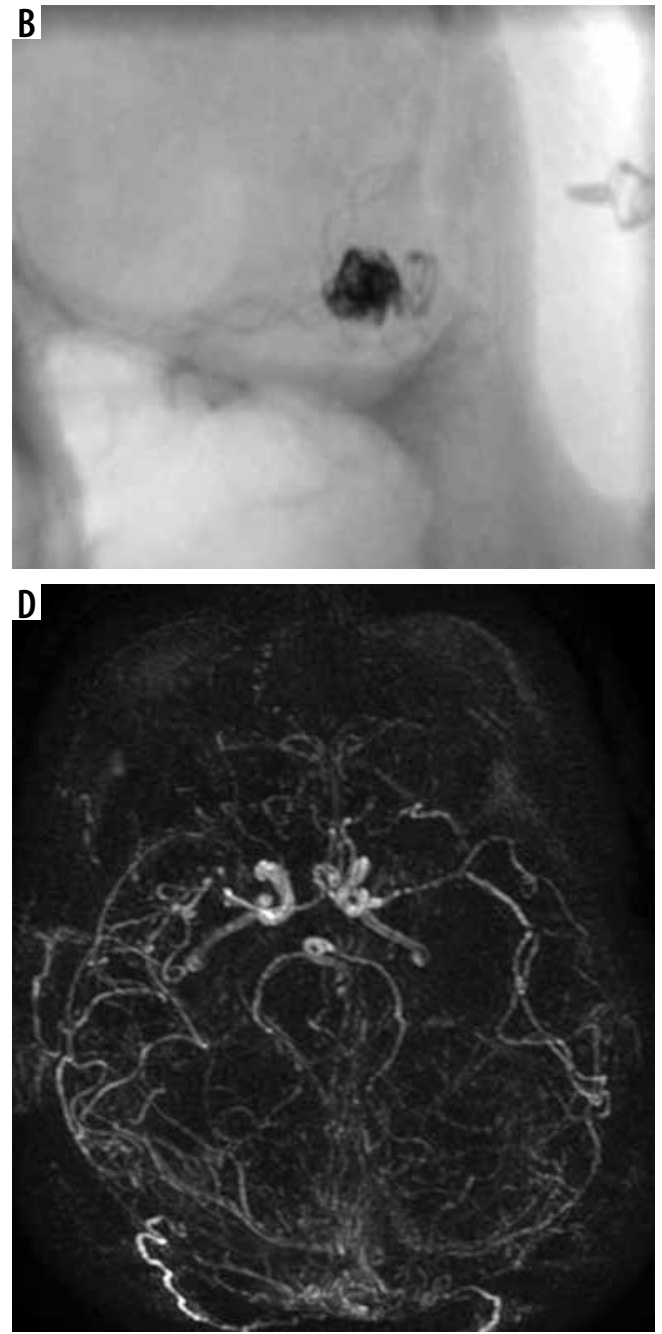

on modified Rankin Scale (mRS), and two patients with 2 points on mRS. Delayed clinical follow-up was available for 16 patients, with a mean time of follow-up of 2.9 \pm 2.4 years. Thirteen patients scored 0 points on $\mathrm{mRS}$, two patients scored 1 point, and one patient scored 4 points, for the mean of $0.6 \pm 1.2$ points.

The overall probability of any incident-free survival was $90.3 \%$; in the group with SAH it was $80 \%$ and in the group without SAH $95.2 \%$. The total probability of severe complications (intraprocedural bleeding and thromboembolic complications) was $20 \%$ (Figure 3 ).

\section{Discussion}

MCA aneurysms were considered challenging to treat by endovascular approach, probably due to the anatomy of MCA. Nearly $90 \%$ of MCA aneurysms are located in the M1 segment division; from $3.57 \%$ to $13.33 \%$ in distal M2 segment divisions [13]. Thus, aneurysms localised in the MCA trunk division may incorporate the enbranchnig vessel, which makes the procedure difficult [5]. Developments in imaging techniques allowed for better assessment of MCA anatomy and more appropriate use of adjunctive devices. The introduction of compliant balloons and 

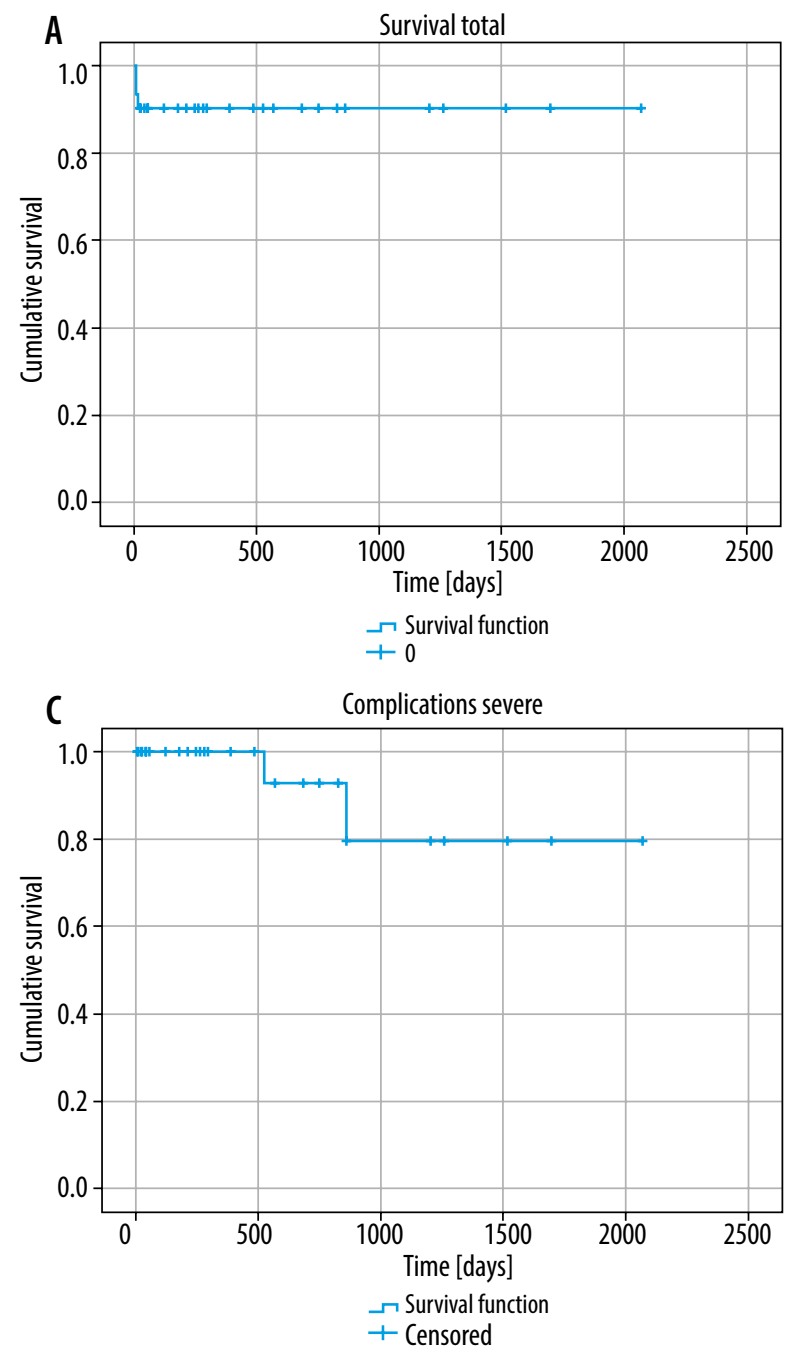

self-expanding stents to clinical practice has changed the approach to wide-necked aneurysms. New devices that aim to increase the share of MCA aneurysms treated endovascularly are constantly being developed. Devices like pCONus (Phenox, Bochum, Germany) and PulseRider (Pulsar Vascular, Los Gatos, CA, USA) are used as an alternative to double-stenting methods to treat wide-necked aneurysms located in arterial bifurcations $[14,15]$. Two cases treated with pCONus are presented in this series. Another one is the Woven EndoBridge, an intraluminal device that is used as an alternative to coils [16].

Previously endovascular approach was also more likely to cause thromboembolic complications. Development of new anticoagulation treatments has largely contributed to limiting of those events [17]. A randomised trial points out that coiling may be more beneficial for patients with $\mathrm{SAH}$ in different localisations compared to microsurgical treatment [18]. However, it may differ in MCA aneurysms. Recent studies have shown that endovascular treatment may be a proper approach in MCA aneurysm treatment after considering neurosurgery [7]. The results of this study are similar to those previously published.

The aneurysm morphology measurements showed no differences between ruptured and unruptured aneurysms. Ruptured aneurysms had a tendency to be larger (median

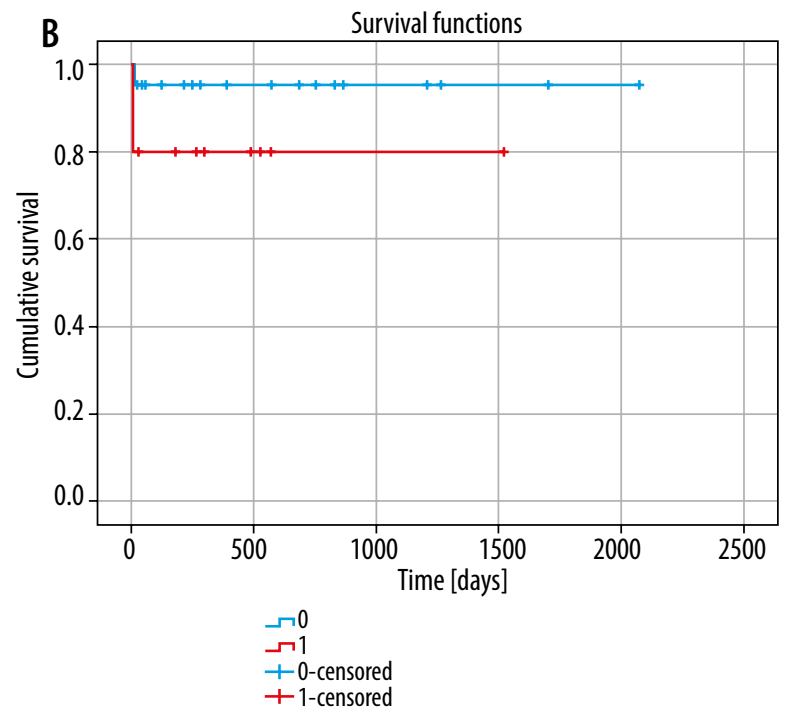

Figure 3. Kaplan-Meier event-free survival courses for patients undergoing middle cerebral artery aneurysms endovascular treatment. Overall survival free any events $(A)$ in patients with and without subarachnoid haemorrhage (B). Cumulative survival freedom for patients with complications - bleeding and thromboembolic events (C)

volumes 20.25 vs. $69.42 \mathrm{~mm}^{3} ; p=0.21$ ), but this parameter differs between studies $[19,20]$. It may be due to the fact that most of the studies include rather limited series of MCA aneurysms. Kadkhodayan et al. demonstrated in their study with the largest series of 346 aneurysms that the mean size of ruptured aneurysm was significantly greater [21]. The median aneurysm neck width was $3.44 \mathrm{~mm}$, which is similar to the results other studies $[17,22]$. Table 2 presents a comparison of recent studies concerning MCA aneurysms treatment. Our study also shows that M1 length can contribute to MCA aneurysm rupture. Haemodynamic factors are a known contributor to both aneurysm formation and rupture. No previous clinical study has found any correlation of M1 length and rupture of the aneurysm; however, M1 length has been proven to be associated with MCA aneurysm formation [23]. Further studies on a larger group of patients are needed to determine its clinical significance.

In $65 \%$ of patients complete occlusion of the aneurysm was achieved. Ruptured aneurysms were more difficult to occlude, but without statistical significance. These results were convergent with previous studies.

Thromboembolic events are considered to be the most common complication during aneurysm coiling [27]. In our study thrombus formation occurred in $5 \%$ of cases. 
Table 2. Comparison of recent studies of endovascular treatment of middle cerebral artery aneurysms. RR1 - Raymond-Roy class I, RR2 - Raymond-Roy class II, RR3 - Raymond-Roy class III

\begin{tabular}{|c|c|c|c|c|c|}
\hline Parameters & This study & Link et al. [17] & Kadkhodayan et al. [24] & Kim et al. [25] & Abla et al. [26] \\
\hline \multicolumn{6}{|l|}{ Demographic statistics } \\
\hline Mean age (years) & $56.15( \pm 13.86)$ & $57( \pm 15)$ & - & 56.70 & $60.27( \pm 10.77)$ \\
\hline Males, $n(\%)$ & $18(45)$ & $26(27.96)$ & $95(27.46)$ & $13(43.33)$ & $10(29.61)$ \\
\hline Female, $n(\%)$ & $22(55)$ & $67(67.04)$ & $251(72.54)$ & $17(56.67)$ & $23(69.70)$ \\
\hline Number of aneurysms & 41 & 94 (93 cured) & 346 (341 cured) & 30 & 34 \\
\hline \multicolumn{6}{|l|}{ Aneurysm statistics } \\
\hline Ruptured, $n(\%)$ & $18(43.90)$ & $40(43.01)$ & $95(27.46)$ & $3(10)$ & $15(44.12)$ \\
\hline Unruptured, $n(\%)$ & $23(56.10)$ & $53(56.98)$ & $251(72.54)$ & $27(90)$ & $19(55.88)$ \\
\hline Retreatments, $n(\%)$ & $4(9.76)$ & $6(6.45)$ & $19(5.49)$ & - & $7(20.59)$ \\
\hline \multicolumn{6}{|l|}{ Diameters (mm) } \\
\hline Maximal diameter & $4.71( \pm 2.63)$ & $6.01( \pm 2.73)$ & 6.6 & - & $10.55( \pm 7.50)$ \\
\hline Maximal neck width & $3.44( \pm 1.64)$ & $3.25( \pm 1.20)$ & 3.0 & - & $3.39( \pm 1.41)$ \\
\hline Aspect ratio & $1.15( \pm 0.77)$ & $1.87( \pm 0.61)$ & - & - & $3.18( \pm 2.10)$ \\
\hline \multicolumn{6}{|l|}{ Treatment method, $n(\%)$} \\
\hline Coil embolisation & $22(50.00)$ & $50(53.76)$ & $86(24.86)$ & $17(56.80)$ & $21(61.76)$ \\
\hline $\begin{array}{l}\text { Stent - assisted (stenting } \\
\text { + stenting and coiling) }\end{array}$ & $14(31.82)$ & $19(20.43)$ & $26(7.51)$ & $3(10.00)$ & $11(33.33)$ \\
\hline Balloon assisted & $5(11.36)$ & $24(25.81)$ & $230(66.47)$ & $2(6.70)$ & $1(3.00)$ \\
\hline Other & $\begin{array}{c}2 \text { - flow diverter (4.55) } \\
1 \text { - pCONus }(2.27 \%)\end{array}$ & - & $\begin{array}{l}4 \text { flow diversion } \\
\text { pipeline (1.16) }\end{array}$ & $\begin{array}{c}8 \text { double } \\
\text { microcatheter }(26.70)\end{array}$ & 2 ICA stenting (6.10) \\
\hline \multicolumn{6}{|l|}{ Procedure outcomes, $n(\%)$} \\
\hline RR1 & $26(63.40)$ & $56(60.21)$ & \multirow{2}{*}{$\begin{array}{c}324(96.14) * \text { complete } \\
\text { or nearly complete }\end{array}$} & \multirow[t]{2}{*}{$28(93.33))^{*}$ complete } & $10(29.40)$ \\
\hline RR2 & $9(22.00)$ & $25(26.88)$ & & & $15(44.10)$ \\
\hline RR3 & $6(14.60)$ & $9(9.67)$ & $13(3.86)$ & $2(6.67) *$ residual aneurysm & $7(20.60)$ \\
\hline \multicolumn{6}{|c|}{ Complications (intraprocedural), $n(\%)$} \\
\hline TE and strokes & $2(5.0)$ & $18(19.35)$ & $47(13.60)$ & $2(6.67)$ & $4(12.12)$ \\
\hline $\begin{array}{l}\text { Haemorrhages } \\
\text { and aneurysm ruptures }\end{array}$ & $2(5.0)$ & $2(2.15)$ & $9(2.60)$ & 0 & $7(21.21)$ \\
\hline Coil relocation & $2(5.0)$ & $2(2.15)$ & - & $1(3.33)$ & - \\
\hline Artery dissection & $1(2.5)$ & $1(1.08)$ & - & 0 & $2(6.06)$ \\
\hline
\end{tabular}

In other recent studies, thromboembolism seems to be a much more common complication. A comparison of complications is also presented in Table 2.

Limitations of this study include its retrospective nature, limited group of patients, and long duration of observation, during which the devices used to perform the procedures were constantly changing.

\section{Conclusions}

Endovascular treatment of MCA aneurysms is feasible. Ruptured MCA aneurysms may be treated endovascularly with similar effects as unruptured MCA aneurysms. The complication rate of such treatment is low.

\section{Conflict of interest}

The authors report no conflict of interest. 


\section{References}

1. Huttunen T, von und zu Fraunberg M, Frösen J, et al. Saccular intracranial aneurysm disease. Neurosurgery 2010; 66: 631-638.

2. Rinne J, Hernesniemi J, Niskanen M, Vapalahti M. Analysis of 561 patients with 690 middle cerebral artery aneurysms: anatomic and clinical features as correlated to management outcome. Neurosurgery 1996; 38: 2-11.

3. Deruty R, Pelissou-Guyotat I, Mottolese C, Amat D. Management of unruptured cerebral aneurysms. Neurol Res 1996; 18: 39-44.

4. Regli L, Uske A, de Tribolet N. Endovascular coil placement compared with surgical clipping for the treatment of unruptured middle cerebral artery aneurysms: a consecutive series. J Neurosurg 1999; 90: 1025-1030.

5. Rodríguez-Hernández A, Sughrue ME, Akhavan S, et al. Current management of middle cerebral artery aneurysms: surgical results with a "clip first" policy. Neurosurgery 2013; 72: 415-427.

6. Smith TR, Cote DJ, Dasenbrock HH, et al. Comparison of the efficacy and safety of endovascular coiling versus microsurgical clipping for unruptured middle cerebral artery aneurysms: a systematic review and meta-analysis. World Neurosurg 2015; 84: 942-953.

7. Eboli P, Ryan RW, Alexander JE, Alexander MJ. Evolving role of endovascular treatment for MCA bifurcation aneurysms: case series of 184 aneurysms and review of the literature. Neurol Res 2014; 36: 332-338.

8. Horowitz M, Gupta R, Gologorsky Y, et al. Clinical and anatomic outcomes after endovascular coiling of middle cerebral artery aneurysms: report on 30 treated aneurysms and review of the literature. Surg Neurol 2006; 66: 167-171; discussion 171.

9. Brinjikji W, Rabinstein AA, Nasr DM, et al. Better outcomes with treatment by coiling relative to clipping of unruptured intracranial aneurysms in the United States, 2001-2008. Am J Neuroradiol 2011; 32: 1071-1075.

10. Qureshi AI, Vazquez G, Tariq N, et al. Impact of International Subarachnoid Aneurysm Trial results on treatment of ruptured intracranial aneurysms in the United States. J Neurosurg 2011; 114: 834-841.

11. de Rooij NK, Linn FHH, van der Plas JA, et al. Incidence of subarachnoid haemorrhage: a systematic review with emphasis on region, age, gender and time trends. J Neurol Neurosurg Psychiatry 2007; 78: 1365-1372.

12. Weir B, Disney L, Karrison T. Sizes of ruptured and unruptured aneurysms in relation to their sites and the ages of patients. J Neurosurg 2002; 96: 64-70.

13. Brzegowy P, Polak J, Wnuk J, et al. Middle cerebral artery anatomical variations and aneurysms - retrospective study based on computed tomography angiography findings. Folia Morphol (Warsz) 2018; 77: 434-440.

14. Aguilar-Perez M, Kurre W, Fischer S, et al. Coil occlusion of wideneck bifurcation aneurysms assisted by a novel intra- to extra-aneurysmatic neck-bridging device (pCONus): initial experience. Am J Neuroradiol 2014; 35: 965-971.

15. Mukherjee S, Chandran A, Gopinathan A, et al. PulseRider-assisted treatment of wide-necked intracranial bifurcation aneurysms: safety and feasibility study. J Neurosurg 2017; 127: 61-68.

16. Lv X, Zhang Y, Jiang W. Systematic review of woven endobridge for wide-necked bifurcation aneurysms: complications, adequate oc- clusion rate, morbidity, and mortality. World Neurosurg 2018; 110 : 20-25.

17. Link TW, Boddu SR, Hammad HT, et al. Endovascular treatment of middle cerebral artery aneurysms: a single center experience with a focus on thromboembolic complications. Interv Neuroradiol 2018; 24: 14-21.

18. McDougall CG, Spetzler RF, Zabramski JM, et al. The barrow ruptured aneurysm trial. J Neurosurg 2012; 116: 135-144.

19. Dhar S, Tremmel M, Mocco J, et al. Morphology parameters for intracranial aneurysm rupture risk assessment. Neurosurgery 2008; 63: 185-197.

20. Grochowski C, Litak J, Kulesza B, et al. Size and location correlations with higher rupture risk of intracranial aneurysms. J Clin Neurosci 2018; 48: 181-184.

21. Kadkhodayan Y, Delgado Almandoz JE, Fease JL, et al. Endovascular treatment of 346 middle cerebral artery aneurysms. Neurosurgery 2015; 76: 54-61.

22. Varble N, Rajabzadeh-Oghaz H, Wang J, et al. Differences in morphologic and hemodynamic characteristics for "PHASES-Based" intracranial aneurysm locations. AJNR Am J Neuroradiol 2017; 38 : 2105-2110.

23. da Cunha CEG, da Cunha Correia C. Middle cerebral artery extension and the risk for aneurysmal disease. J Neurol Sci 2018; 390: 219-221.

24. Kadkhodayan Y, Delgado Almandoz JE, Fease JL, et al. Endovascular treatment of 346 middle cerebral artery aneurysms: results of a 16-year single-center experience. Neurosurgery 2015; 76: 54-60; discussion 60-1.

25. Kim KH, Cha KC, Kim JS, Hong SC. Endovascular coiling of middle cerebral artery aneurysms as an alternative to surgical clipping. J Clin Neurosci 2013; 20: 520-522.

26. Abla AA, Jahshan S, Kan P, et al. Results of endovascular treatment of middle cerebral artery aneurysms after first giving consideration to clipping. Acta Neurochir (Wien) 2013; 155: 559-568.

27. Vendrell JF, Menjot N, Costalat V, et al. Endovascular treatment of 174 middle cerebral artery aneurysms: clinical outcome and radiologic results at long-term follow-up. Radiology 2009; 253: 191-198. 